Technical Report Documentation Page

\begin{tabular}{|c|c|}
\hline $\begin{array}{l}\text { 1. Report No. } \\
\qquad \text { DOT HS } 808989\end{array}$ & 3. Recipient's Catalog No. \\
\hline \multirow{2}{*}{$\begin{array}{l}\text { 4. Title and Subtitle } \\
\text { Evaluation of a Day Reporting Center for Repeat DWI Offenders }\end{array}$} & $\begin{array}{l}\text { 5. Report Date } \\
\text { August } 1999\end{array}$ \\
\hline & 6. Performing Organization Code \\
\hline \multirow{2}{*}{$\begin{array}{l}\text { 9. Performing Organization Name and Address } \\
\text { Mid-America Research Institute } \\
611 \text { Main Street } \\
\text { Winchester, MA } 01890\end{array}$} & 10. Work Unit No. (TRAIS) \\
\hline & $\begin{array}{l}\text { 11. Contract or Grant No. } \\
\text { DTNH22-95-C-05050 }\end{array}$ \\
\hline $\begin{array}{l}\text { 12. Sponsoning Agency Name andAddress } \\
\text { National Highway Traffic Safety Administration } \\
\text { Office of Research and Traffic Records } \\
4007^{\text {th }} \text { Street, S.W. } \\
\text { Washington, DC } 20590\end{array}$ & 14. Sponsoring Agency Code \\
\hline
\end{tabular}

15. Supplementany Notes

Amy Berning was the Contracting Officer's Technical Representative (COTR) for this project.

16. Abstract

Describes and evaluates the effectiveness of a Day Reporting Center (DRC) in reducing the DWI recidivism of repeat DWI offenders. Also examines the effect of the DRC program in reducing the cost of post-conviction sanctioning operations, and in relieving the pressures on jail facilities in carrying out the court-imposed sanctions. Found that the DRC program was no more effective in reducing recidivism than was a comparison standard probation program in use by the study jurisdiction. However, the DRC program was more cost-effective and helped reduce pressure on an already over-taxed county jail system.

17. Key Words

DWI, impaired drivers, sanctions, sentencing, probation, recidivism, court procedures, program evaluation, day reporting center
18. Distribution Statement

This report is available from the National Technical Information Service, Springfield, Virginia 22161 (703) 605-6000
19. Security classif. (of this repont)
20. Security Classif. (of this page)
21. No. of Pages 


\section{ACKNOWLEDGMENTS}

The authors wish to acknowledge the assistance we received from our many collaborators in Maricopa County, Arizona.

The Day Reporting Center (DRC) is a program of the Maricopa County Adult Probation Department. We wish to thank Norman Helber, Chief Probation Officer and Dorothy Faust, former Deputy Chief Probation Officer for Programs for their willingness to subject their program to evaluation and for facilitating the research project. Lee Brinkmoeller, Probation Officer Supervisor, was in charge of the DRC during the period evaluated and was instrumental to the conduct of the study. His openness and insight were instrumental to the success of the project.

The Arizona Motor Vehicles Division provided the driver record data used in the recidivism analysis. Russell K. Pearce, Division Director, and F. William (Rick) Griffeth, Assistant Director, were most helpful in approving our request and steering it through the necessary reviews. Hilton Ishimoto performed the computer programming which was necessary to fulfilling our request.

Alberto Gutier, Director of the Arizona Governor's Office of Community and Highway Safety and Tila Rendon of his staff were most helpful in supporting the project and facilitating appropriate contacts.

To the persons mentioned above and many others who helped, we extend our sincere thanks. 


\section{TABLE OF CONTENTS}

ACKNOWLEDGMENTS $\ldots \ldots \ldots \ldots \ldots \ldots \ldots \ldots \ldots \ldots \ldots \ldots$ i

TABLE OF CONTENTS $\ldots \ldots \ldots \ldots \ldots \ldots \ldots \ldots \ldots \ldots \ldots \ldots \ldots \ldots$ ii

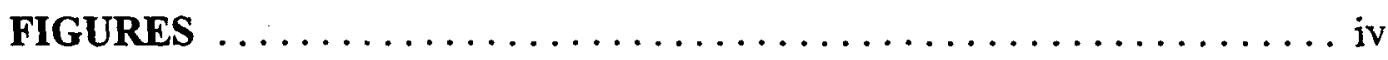

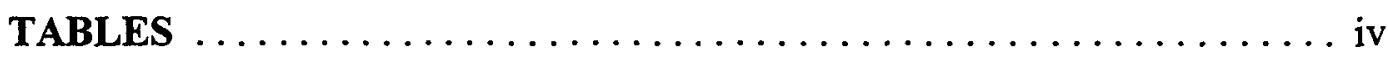

EXECUTIVE SUMMARY $\ldots \ldots \ldots \ldots \ldots \ldots \ldots \ldots \ldots \ldots \ldots \ldots$

1 - INTRODUCTION $\ldots \ldots \ldots \ldots \ldots \ldots \ldots \ldots \ldots \ldots \ldots \ldots \ldots \ldots \ldots \ldots \ldots$

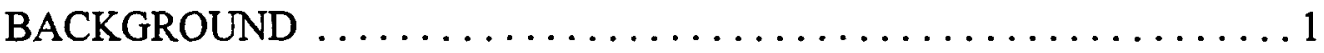

PROJECT SCOPE AND APPROACH $\ldots \ldots \ldots \ldots \ldots \ldots \ldots \ldots \ldots \ldots$

ORGANIZATION OF THE REPORT $\ldots \ldots \ldots \ldots \ldots \ldots \ldots \ldots \ldots$

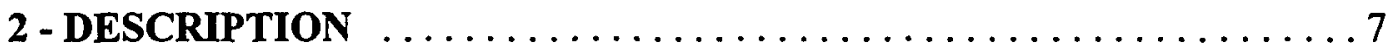

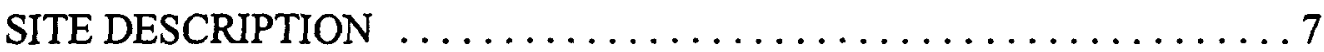

Population and Socio-Economic Factors ................ 7

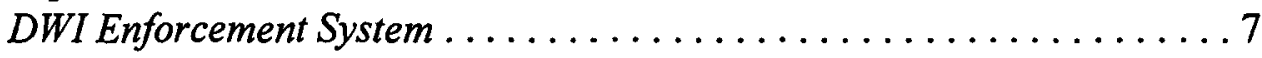

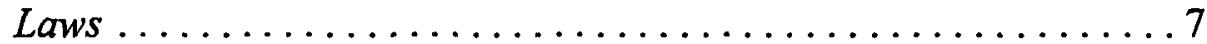

Enforcement $\ldots \ldots \ldots \ldots \ldots \ldots \ldots \ldots \ldots \ldots \ldots \ldots \ldots \ldots$

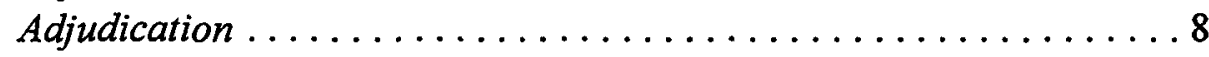

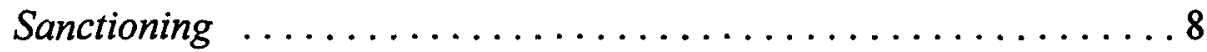

PROGRAM DESCRIPTION $\ldots \ldots \ldots \ldots \ldots \ldots \ldots \ldots \ldots \ldots \ldots$

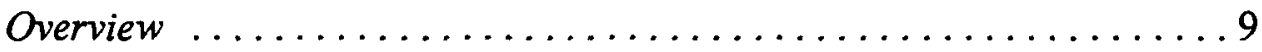

Offender Case Flow and Processing $\ldots \ldots \ldots \ldots \ldots \ldots \ldots \ldots$

Screening ................................... 10

Acceptance, Cancellation, and Placement ............... 12

Orientation .................................. 13

Client Assessment ............................. 13

Client Contact ............................... 13

Employment and Collections Procedure ................ 14

Disciplinary Action ........................... 15

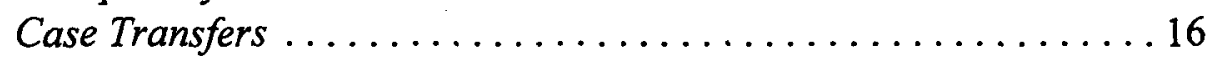

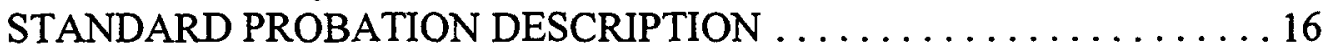

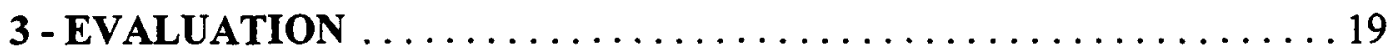

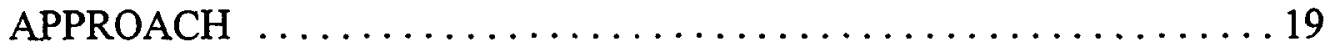

PROGRAM OPERATION $\ldots \ldots \ldots \ldots \ldots \ldots \ldots \ldots \ldots \ldots \ldots \ldots$ 


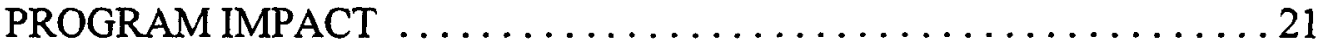

Experiment Design .............................. 21

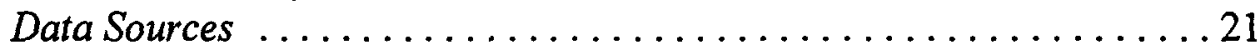

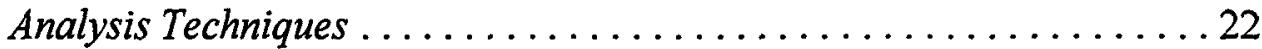

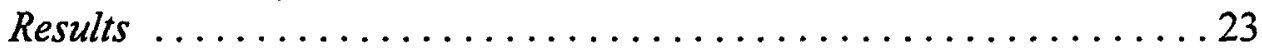

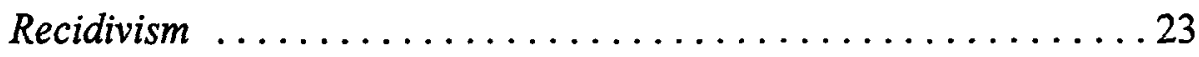

Offender Characteristics .......................25

SUMMARY AND CONCLUSIONS $\ldots \ldots \ldots \ldots \ldots \ldots \ldots \ldots \ldots \ldots \ldots$

4 - CONCLUSIONS AND RECOMMENDATIONS $\ldots \ldots \ldots \ldots \ldots \ldots 27$

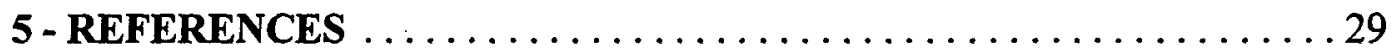

APPENDIX A - Standards for DRC Caseload Documentation .......... 31 


\section{FIGURES}

Figure 3-1: Raw Recidivism Curves for the DRC Group and the Comparison

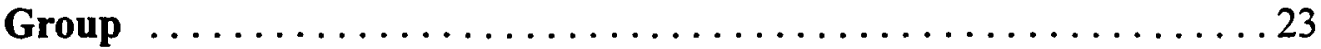

Figure 3-2: Percent of Combined Group Recidivating After

Two Years By Number of Prior DWIs .................. 24

\section{TABLES}

Table 1-1: One-Year Recidivism Rates for First Offenders and Repeat Offenders, Statewide Data from Various Sources ............. 2

Table 3-1: Number of Study DWIs Entering the DRC Program by Year . . 20

Table 3-2: Mean Months Sentenced to Probation and Mean Months Served by DRC Subjects Studied 20 


\section{EXECUTIVE SUMMARY}

This report summarizes the results of a project designed to describe and evaluate a selected alternative sanction program for repeat DWI offenders who had been arrested for and charged with a felony DWI offense. The selected countermeasure, a Day Reporting Center (DRC) is a highly structured non-residential facility that provides supervision, reporting, employment, counseling, education and community resource referrals to probationers. The DRC studied was operated by the Adult Probation Department of the Maricopa County, Arizona Superior Court and provided a continuum of correctional services to augment intensive supervision, residential programs (e.g., halfway houses, work release centers, etc.), and regular supervision. The evaluation addressed the effectiveness of the Maricopa County DRC in reducing DWI recidivism, in reducing the cost of post-conviction sanctioning operations, and in relieving the pressures on jail facilities in carrying out the court-imposed sanctions.

The study found that the DRC program was no more effective in reducing recidivism than was a standard probation program in use by the study jurisdiction. Both programs had a recidivism rate of about $8 \%$ after two years, quite low for this group of offenders. However, other measures of effectiveness yielded more positive results.

The goal of the DRC program is not only related to recidivism, but rather is intended to assist in the reintegration of these offenders into society. This includes insistence on employment, demonstration of responsibility through at least partial payment of fees, and participation in educational programs as appropriate. Further, the cost of providing correctional services through DRC is significantly less than jail. In Maricopa County it costs $\$ 36.79$ per day per individual to keep an offender in jail versus $\$ 19.69$ per day for $D R C$. The DRC offender typically is incarcerated for sixty fewer days than comparison group members who completed their period of incarceration followed by standard probation. This $\$ 17.10$ per day savings translates into $\$ 1,026$ per offender if they are in DRC rather than jail.

Another benefit is that participants become employed and thus provide support for themselves and their families. Undereducated adults benefit from additional educational services. Treatment needs are addressed. Consequences for uncooperative or non-compliant behaviors are immediately imposed.

This study also sought to determine whether DWI offenders were appropriate for a DRC-type program, which is intended for offenders thought to be of low risk of committing violent crimes. Interviews with program staff indicated that DWI offenders did participate in the DRC program and were appropriate participants. One area where the program might be modified to more effectively deal with DWI offenders is in the treatment aspect of the program. The vast majority of these severe DWT offenders are alcohol abusers rather than abusers of other drugs. The program studied in this project included a general substance abuse treatment component. If 
the DWI caseload in DRC were expanded, then it would be appropriate to screen for problem drinking and implement treatment modalities specifically tailored to alcohol abuse and drinking driving.

The study found that there had been some reluctance to use DRC for DWI offenders because, though by traditional measures they met the criteria of low-risk offenders, they were believed to pose a risk to society because of potential drinking and driving while they were participating in the program. However, this study indicates that DWI offenders pose no greater risk than those who serve their full jail or prison terms, and that it costs society less to deal with them in DRC than in jail or prison.

We recommend that consideration be given to referring more DWI offenders to DRC-type programs and that the DRC treatment program be modified to include a treatment regimen which is structured to deal specifically with alcohol abuse and driving. 


\section{1 - INTRODUCTION}

This report summarizes the results of a project designed to describe and evaluate a selected alternative sanction programs for repeat DWI offenders. The project was conducted for the National Highway Traffic Safety Administration under Contract Number DTNH22-95-C-05050 entitled "Develop and Test Countermeasures for Repeat DWI Offenders." The objective of this project was to identify, test, and evaluate a promising countermeasure for drinking after driving by repeat DWI ${ }^{1}$ offenders.

\section{BACKGROUND}

There is a considerable body of research pointing to repeat DWI offenders as a significant component of the drinking-driving problem in this country. For example, a study by Donovan et al. (1990) examined the driver records of 39,011 Washington State drivers and found that nearly $20 \%$ of the drivers with prior DWIs were arrested again during a three-year follow-up period, compared to only $2 \%$ of the drivers with no priors.

Other studies of statewide data have also found DWI offenders with prior DWI offenses tend to have higher recidivism rates than do DWI offenders with no priors, although the ratio of the recidivism rate for those with priors to the rate for those with no priors is not nearly so dramatic as the 10 to 1 ratio found by Donovan and associates (Table 1-1).

Studies of DWIs at the local level are in general agreement with these statewide studies. For example, as a part of our NHTSA-sponsored study of alternative sanctions for repeat DWI offenders (Jones, Wiliszowski, and Lacey, 1997), we examined the recidivism rates of drivers with and without prior DWIs in two jurisdictions. We found that in one jurisdiction (Milwaukee, Wisconsin), not only were the one-year recidivism rate of drivers with priors considerably higher than those without priors, but that the recidivism rate increased as the number of priors increased. For example, the adjusted one-year recidivism rate of a group of DWIs with two priors receiving traditional sanctions for their index offense was nearly twice that of such DWIs with one prior $(15.2 \%$ versus $8.0 \%)$.

There is also evidence that drivers with prior DWIs are more likely to be involved in severe traffic crashes than are other drivers. Data from FARS (Fell, 1991) show that, in $1988,3.3 \%$ of all licensed drivers had been arrested for DWI in the past three

${ }^{1}$ In this report, the term "DWI" is used generically to describe driving with an illegally high blood alcohol concentration (BAC). Other terms that are used by some jurisdictions include DUI (driving under the influence) and OMVI (operating a motor vehicle while intoxicated), among others. 


\section{Table 1-1: One-Year Recidivism Rates for First Offenders and Repeat Offenders, Statewide Data from Various Sources}

\begin{tabular}{|llllll|}
\hline \multicolumn{1}{|c}{ Location } & \multicolumn{1}{c}{ Group } & $\begin{array}{c}\text { Subsequent } \\
\text { Event }\end{array}$ & $\begin{array}{c}\text { Priors } \\
(\%)\end{array}$ & $\begin{array}{c}\text { No Priors } \\
(\%)\end{array}$ & Ratio \\
\hline California' & $\begin{array}{l}\text { BAC test refusers } \\
\text { who also were con- } \\
\text { victed of DWI }\end{array}$ & DWI & 12 & 10 & 1.20 \\
Illinois & BAC test refusers & $\begin{array}{l}\text { DWI or re- } \\
\text { fusal }\end{array}$ & 19 & 13 & 1.46 \\
Tennessee $^{2}$ & DWls & DWI & 15 & 10 & 1.50 \\
California $^{3}$ & DWIs & Composite & 22 & 17 & 1.29 \\
\hline
\end{tabular}

Notes:

1. Jones, Joksch, and Wiliszowski, 1991

2. Jones, et al., 1988

3. Arstein-Kerslake and Peck, 1985

4. Composite recidivism includes at least one of the following: nighttime accident, alcohol-related accident (from police report), and major traffic conviction (DUI, reckless, hit and run).

years, but $5.7 \%$ of all fatally injured drivers had been arrested for DWI in the past three years. This indicates that drivers with prior DWIs were over-represented in fatal crashes by a factor of about 1.8 .

Clearly, then, there is a need for countermeasures targeted specifically at repeat DWI offenders. We have conducted three recent NHTSA-sponsored projects aimed at identifying promising countermeasures for such individuals. The first of these projects, "Evaluation of Alternative Programs For Repeat DWI Offenders" (cited above), involved an examination of programmatic and evaluative literature on the effectiveness of countermeasures for repeat DWIs, the selection for evaluation of two promising countermeasures employing alternatives to jail, and the evaluation of these two countermeasures. The second recent project "Determine Reasons for Repeat Drinking and Driving," (Wiliszowski et al., 1996) was aimed at determining when, where, how and why individuals convicted of drunk driving repeat the offense; ascertaining what countermeasures these individuals have encountered and the extent of their effectiveness against recidivism; and identifying promising countermeasures to reduce DWI recidivism among repeat offenders. The third recently completed project, "Evaluation of an Individualized Sanctioning Program for DWI Offenders," (Jones and Lacey, 1998) examined countermeasures for both first offenders and repeat offenders and identified a promising program of individualized sanctions for both groups of DWI offenders. We are also currently involved in a third project 
(under NHTSA's Partners in Progress program) that is implementing and evaluating a DUI court program for drivers convicted of a repeat DWI offense.

This project is a continuation of this research, which will together provide additional knowledge for use by jurisdictions in developing countermeasures suitable to their own operational environments.

\section{PROJECT SCOPE AND APPROACH}

This project sought to select and test the effectiveness of a countermeasure that appeared to have potential for reducing the incidence of drinking-driving by repeat DWI offenders. The site selection criteria included the following elements and were tailored and expanded to accommodate the specific requirements for the countermeasure to be studied.

1. Adequate sample size of repeat offenders to institute a viable countermeasure program and to allow for detection of a program effect, if present.

2. Willingness of appropriate agencies within the community to implement the countermeasure and subject the program to evaluation.

3. Availability of resources necessary to competently implement the countermeasure and maintain it throughout the period of evaluation.

4. Availability of useable data which would permit countermeasure impact evaluation, and willingness and ability to provide those data in an appropriate format.

5. Absence of plans to begin implementation of other countermeasure activity, legislative and legal changes, special programs, additional enforcement programs or other measures which would compound countermeasure evaluation or mask the effect of the countermeasure under study.

6. Willingness to collect and provide additional process data which will enable a full description of the implementation process and allow for what amounts to a process evaluation.

Based on these criteria, we selected Maricopa County, Arizona as the site and the Adult Probation Department of the Maricopa County Superior Court (APD) as the implementing agency. The APD has a long history of developing and evaluating innovative programs for persons with alcohol- and drug-related offenses. The APD had been operating a Day Reporting Center (DRC) for several years, but had not had the opportunity to evaluate the program's effectiveness in dealing with DWI offenders. Past operation of the program made available data that could be used in tracking program participants for several years after their entry into the program, thus allowing a stronger experimental design for evaluating the program.

Day Reporting Centers (DRC) have been used in several jurisdictions as an alternative for jail for low-risk offenders convicted of a variety of offenses (Morris and Tonry, 1990; U.S. Department of Justice, 1990). In general, a DRC is a highly 
structured non-residential facility that provides programs consisting of supervision, reporting, employment, counseling, education and community resource referrals to probationers. DRCs can be developed into a continuum of correctional services to augment intensive supervision, residential programs (e.g., halfway houses, work release centers, etc.), and regular supervision. We had identified the DRC approach as a candidate for evaluation in the Alternative Sanctions project, but it was dropped from consideration in that project because of a lack of data for performing a scientific evaluation and because of a lack widespread use of the approach at that time.

The particular form of DRC program that we studied in this project was designed to serve two purposes: (1) reintegrate the offenders into society and thereby reduce the likelihood of future DWI incidents, and (2) reduce the cost of maintaining offenders in jail for the full period of their sentence. The part of the study that was concerned with recidivism used a research design that compared the recidivism rates of a group of offenders who were assigned to the DRC program to the rates of a group of offenders who were assigned to a standard probation program used by the APD for offenders in a general. Offenders in both groups had been charged and convicted of a serious DWI offense, and had initially been sentenced to a period of incarceration, usually four months.

The DRC group of offenders was assigned to the DRC program at the beginning of their probationary period. They were assessed for treatment, job skills and educational needs at the beginning of DRC, and then placed into specific programs as appropriate. While in the DRC program, the offenders received very frequent contact from their probation officer (a minimum of two contacts a week during most of the program) and had to seek and obtain employment. Participation in DRC generally lasted one to two months and was given in lieu of a similar period of incarceration. For example, a DRC participant who received a jail sentence of four months might serve two months in jail followed by two months in the DRC program. After completion of DRC, participants were placed on standard probation for the remainder of their period of probation, averaging about four years.

The comparison group of offenders assigned to standard probation served their full period of incarceration, usually four months, followed by about four years on standard probation. Standard probation usually included some form of treatment or counseling at the outset and monthly visits with the probation officer. The probation officer also attempted to visit probationers at their home about four times per year.

Thus, the evaluation reported here addresses the effectiveness of the selected DRC in reducing DWI recidivism, in reducing the cost of post-conviction sanctioning operations, and in relieving the pressures on jail facilities in carrying out the court-imposed sanctions.

\section{ORGANIZATION OF THE REPORT}

A detailed description of the program site and the $\mathrm{DRC}$ program is presented in Chapter 2. Chapter 3 describes the design and results of the evaluation, and Chapter 
4 presents the overall conclusions of the project. A listing of pertinent reference material follows in Chapter 5. An Appendix describing the standards used by the APD for documenting the DRC caseload is also included. 


\section{EVALUATION OF A DAY REPORTING CENTER FOR DWI OFFENDERS}




\section{2 - DESCRIPTION}

\section{SITE DESCRIPTION}

\section{Population and Socio-Economic Factors}

Maricopa County has the largest population of any county in Arizona, 2.7 million, amounting to some $57 \%$ of the population of the entire state in 1998 . The county encompasses an area of 9,226 square miles and contains a number of municipalities. The largest of these is the city of Phoenix with a population of 1.2 million, also the largest city in the state. Other cities in the county with a population over 100,000 are Scottsdale, Mesa, and Tempe.

Maricopa County is one of the fastest growing counties in the U.S., increasing $24 \%$ since 1990 and $3 \%$ since 1997 . The median age is 31.1 years with $61 \%$ of the population falling between the ages of 18 and 64 . Twenty-six percent (26\%) of the County's population is under 18 , while $13 \%$ is over 65 . The 1990 U.S. Census reports that $84 \%$ of this population is white, $4 \%$ is black and $12 \%$ other races. The County has a large population of persons of Hispanic origin, estimated at about $16 \%$.

Median household income in Maricopa County was $\$ 37,583$ in 1995 , with $13.8 \%$ of the population was estimated to be in poverty as July 1996. The County has had low unemployment over the past ten years and is in the $3 \%$ range as of this writing.

\section{DWI Enforcement System}

Laws. The population targeted in this study is drivers who have been charged with a felony DWI offense and been convicted in Superior Court in Maricopa County. Though all were originally charged with a felony, they may have been convicted of a felony DWI, more precisely defined as a Class 4 felony in the state statutes, or of a serious misdemeanor DWI in cases where they plead guilty to a lesser offense. Drivers convicted of the felony charge who have two or more prior DWI convictions within a six-year period may be sentenced to $2 \frac{1 / 2}{2}$ to 12 years in prison (not jail) and a fine of not more than $\$ 150,000$. Drivers with three or more prior felony convictions may be sentenced to eight to 12 years in prison. Drivers with two prior DWIs must serve a minimum of four months in prison, and drivers with three or more DWIs must serve a minimum prison term of eight months. Some defendants, though charged with a felony or multiple offenses, may plead guilty and receive four months in jail and probation rather than serve their time in prison.

A limited "furlough" from prison or jail may be granted (for example, to participate in a work release program or a DRC-type program) for those convicted of a felony DWI. Offenders will be placed on probation during the furlough period (see the discussion in the Program Description section below). 
Driver license sanctions are imposed by the Motor Vehicle Department for both the DWI offense and various other administrative infractions that may be coincident with the DWI. However, statutes exclude felony DWIs from assignment to community service in lieu of jail.

Enforcement. DWI laws are enforced by officers from the various municipal agencies and also by the Maricopa County Sheriff's Department and the Arizona Highway Patrol. The Uniform Crime Report (UCR) for 1995 reports that there were 2,183 officers in the city of Phoenix alone as of October 31, 1995. Mesa, Tempe, and Scottsdale together had another 1,061, and the Sheriff's Department had 445. Altogether, we estimate that some 4,000 officers were engaged in enforcing laws of all kinds in Maricopa County during the years covered by this evaluation.

The 1995 UCR also lists 27,708 DWI arrests statewide for reporting jurisdictions having a population of $3,869,000$. This amounts to 7.71 arrests per 1,000 population. So, a rough estimate of the number of DWI arrests for Maricopa County (population 2.4 million in 1996) is $7.71 \times 2,400 \cong 17,400$. This amounts to about four DWI arrests per sworn officer.

Adjudication. Felony DWI cases are prosecuted in Maricopa County by prosecutors from the Maricopa County Attorney's Office. The cases are heard in the Maricopa County division of the Superior Court of Arizona. Cases originally charged as misdemeanor DWIs are generally heard in a lower court which does not have probation services. Thus, all of the cases under consideration in this study are DWI cases which were heard in Superior Court which is served by the Adult Probation Department (APD).

Sanctioning. Felony DWI cases are heard in the Superior Court of Maricopa County. Mandatory prison or jail sentences indicated above are imposed. Additional discretionary components of the sentences vary according to individual judges subject to sentencing guidelines provided by the state court system. Drivers convicted of a felony DWI are incarcerated in one of four prison facilities in Arizona. One of these facilities is in Maricopa County, but Maricopa County offenders may also be sent one of the other three facilities.

Persons who have plea-bargained their offense down to a misdemeanor are incarcerated in the Maricopa County Jail. This facility is plagued by a lack of space for its population, reportedly now crowding some 7,000 adult offenders into space designed for about 3,000. "Tent Cities" have been constructed to help relieve some of the pressure, and the issue of jail overcrowding is a major issue in the County. 


\section{PROGRAM DESCRIPTION}

\section{Overview}

The DRC program is an ongoing program. Its stated purpose is to furlough targeted defendants from incarceration to a program of strict supervision and structured reintegration services. The program provides supervision of furlough-selected defendants from incarceration who have been granted probation by the Maricopa County Superior Court. In contrast to other offenders, DRC program participants are selected from those originally charged with felony DWI, but have plea-bargained down their offense to a misdemeanor DWI. Thus, their incarceration is spent in the Maricopa County jail, rather than a State prison as required of those who were actually convicted of a felony.

The DRC program is designed to provide for the protection of the community with strict community supervision and structured reintegration services. The DRC staff is responsible for the enforcement of terms of probation as well as development of a treatment strategy which is designed to facilitate high need defendants in a variety of areas that will assist in their effective reintegration into society after their lives have been disrupted from incarceration, loss of employment, loss of residence, etc. The DRC program provides for high supervision (daily contact with probation officers, house arrest, increased number of drug and alcohol tests, round the clock supervision) as well as mandatory "programming" for substance abuse, education, employment or other specialized needs. Youthful offender (18-25 years of age) treatment and residential facilities are also utilized.

Defendants are screened before and after sentencing for possible participation in the DRC. If an incarcerated, furlough-eligible defendant appears motivated to change negative behavior, is a nonviolent defendant, and has a residence that can be verified, the defendant is eligible to participate in the program. In cases where a defendant has an unhealthy or transient residence, adult males can be brought directly from jail into the DRC Garfield residential facility. Typically, this occurs during the final 30 to 60 days of the jail sentence. While in the program, defendants are expected to follow structured daily schedules and are considered under house arrest.

During the day, defendants follow an hour-by-hour schedule of courses offered at the DRC and other community-based agencies and/or participate in a job search program until employed. All defendants follow daily schedules. These schedules are based upon the individual needs of each defendant. Unemployed defendants are given five to ten days to obtain employment or are immediately put back into custody.

Courses offered at the DRC address a variety of needs, including drug and alcohol counseling, literacy and GED classes, family and health issues and behavioral health counseling. These courses focus on assisting the defendant in the development of skills needed to successfully integrate into the community. The most efficient and cost-effective means to offer these services is through the use of private, 
nonprofit vendors. In order to attract these agencies, space is provided at the DRC to conduct group and individual counseling services. Providers are allowed to offer these services to non-probation clients as well. In return, the providers are required to offer DRC defendants: priority to services, deferred payments for services, reduced payments for services, and scholarships for the most needy clients.

Probation officer/surveillance officer teams monitor defendants participating in the DRC program. These teams are responsible for developing treatment plans, conducting individual and group counseling sessions and formulating the defendants' daily schedules. Intake screeners, job developers, literacy teachers, and community service coordinators assist these case managers. Defendants are monitored by surveillance and probation officers during the day, night and on weekends. The behavior of the defendants is also scrutinized through collateral contacts, as well as regular urine and breath testing.

Defendants remain in the DRC program until the completion of their original jail sentence but may continue to be supervised in the program if the defendant needs to complete Youthful Offender Program (YOP) treatment or has had problems at the end of the jail phase of DRC. Upon successful completion of the program, the defendants continue under standard or intensive probation supervision. If a defendant fails to complete the program, the defendant is returned to jail to complete the original jail sentence or returned to court for violation proceedings.

The target population for DRC programs include those individuals serving jail as a term of probation with sixty days or less remaining on the jail term (defendants may participate longer if ordered by the Court). Defendants also must be individuals who would benefit from a structured reintegration service and who do not pose a serious risk to the community. No sex offenders are ever admitted to the program.

\section{Offender Case Flow and Processing}

Screening. Once a defendant is determined to be a member of DRC target population, a screening process begins to assess the individual's eligibility. The Furlough Screening Unit screens all defendants given a jail term who are furlougheligible. Each defendant's eligibility for DRC is then reviewed. In order to be eligible for DRC programs, all individuals must meet the following guidelines:

- be furlough-eligible per terms and conditions of probation,

- have an acceptable, verifiable address,

- display a non-violent pattern of behavior,

- have access to transportation,

- be willing to participate in the program per the Compliance Agreement,

- not have charges pending or outstanding warrants that would interfere with participation in the program,

- not have any history of sex offense convictions, and 
- have approval from the prosecuting attorney in those cases where jail is stipulated in the plea agreement.

If a defendant meets the above criteria for DRC participation, the screener conducts an interview and completes a DRC Screening Packet. The packet is then forwarded to DRC Administration. The DRC supervisor, or designate, then reviews each case for acceptance into the program.

A screening officer may reject an application for one or more of the following conditions:

- the defendant has been convicted of escape or any unauthorized absence from any correctional institution or release program in the past,

- the defendant has charges pending and cannot be released from jail. (Exceptions are possible if extradition for a pending charge has been declined by the filing/charging jurisdiction or the defendant has been released on own recognizance),

- the nature and extent of the defendant's criminal history reflects a high probability to re-offend in the community,

- the defendant has not received a favorable recommendation from the field or presentence officer most knowledgeable about the case,

- reliable information indicates that the defendant has a pattern of violent behavior or weapons use,

- the defendant has been formally charged with a criminal act subsequent to commission of the present offense,

- the defendant's present offense involved the use, exhibition, or presence of a firearm, explosive, or other weapon,

- the factual circumstances of the present offense indicate severe violent tendencies,

- Maricopa County Sheriffs office booking information which suggests the defendant's inability to successfully complete the program. This could include disciplinary write-ups by detention personnel,

- the defendant is an illegal alien with a hold by the Immigration and Naturalization Service,

- the defendant is not residing in Maricopa County following release from incarceration, or

- the defendant committed a work furlough program violation.

The DRC must notify the prosecuting attorneys of any defendants serving jail terms as a stipulation of their plea agreement. The DRC support staff sends notice to the assigned prosecuting attorney at least ten days prior to the defendant being placed in the DRC. If there is an objection by the County Attorney, the defendant is considered ineligible for the program. 
Acceptance, Cancellation, and Placement. If all the above conditions are satisfied, a DRC supervisor, or designate, approves the defendant for participation in the program and assigns a supervision team. The screening packet is given to the assigned support staff, and the Order of Release, including a narrative for the Court's consideration, is completed. The Order of Release is completed seven days prior to the scheduled release date of the defendant.

Once the Order of Release is completed, a copy is sent to the assigned furlough screener for the Judge's signature. Work Furlough, Account Services, the Day Reporting Center staff and the Building Administrator of Garfield Residential Center also receive copies.

Once the Judge signs the Order of Release, the order is sent to DRC Administration. DRC Administration sends copies of the Order of Release to the Maricopa County Sheriff's Office Work Box and the Victim Notification Unit. Copies of the signed Order of Release and screening packets are delivered to the assigned supervision team within twenty-four hours of the Judge's signature. The supervision team then verifies appropriateness of the defendant's residence. If the defendant has no residence, but is otherwise appropriate for the program, the supervision team makes every effort to secure a residence or refers the defendant for participation in the Garfield Residential Treatment Program. Once accepted, the DRC probation officer makes arrangements to obtain the defendant's file. For Work Furlough cases, the files are available at the time of the defendant's release.

Cancellations or postponements for entry into the DRC program can result from one or more of the following:

- residence cannot be verified or is considered to be inappropriate,

- County Attorney objects when plea stipulates jail,

- new information, not available at the time of screening, makes the defendant ineligible,

- non-compliance with Work Furlough rules and regulations, or

- violations of jail rules and regulations that require a cancellation.

Before a cancellation is made, a DRC supervisor reviews the case. If it is determined that cancellation is necessary and a Judge has already signed the Order of Release, immediate notification is sent to the Maricopa County Jail, the assigned field probation officer, the DRC team assigned to the case, Administration Account Services and Work Furlough. If the Court orders the defendant into the program per the terms of probation and the defendant is unable to participate, the sentencing Court is immediately notified. After a cancellation has been approved, DRC Administration support staff is notified, and the assigned DRC team returns the original screening packet to the Garfield Center.

After notification, the Maricopa County Sheriff's Office transports DRC defendants to the designated facility for pick-up. When this is not possible, pick-up takes place at the facility where the defendant is housed. The Sheriff's office has the 
defendant's Order of Confinement available for the DRC supervision team at the time of pickup.

The surveillance officer is responsible for the pick-up of the individual. The supervision teams at each DRC site coordinate pick-ups to ensure that orientation begins on time.

Orientation. All defendants complete orientation on the first day they are in the program. The DRC staff explains the program to defendants, answers questions, and addresses any issues that could conflict with an individual successfully completing the DRC. Orientation includes discussion of the program's directive(s), the DRC Compliance Agreement, each individual's terms of probation, educational assessment and weekly schedule. The DRC also uses this opportunity to review the defendant's living conditions, verify employment or current job search, and determine the individual's payment ability. The DRC staff completes a Letter of Understanding with the defendant. The letter is to be signed by the defendant's employer within 5 working days of receipt.

Formal staffings are held every week at a designated time and day of the week. At least one member of the supervision team and one person from each of the treatment components participate. Normally, by the end of the defendant's first week in the program, a priority staffing is held. This helps determine which programs the defendants will participate in and in what sequence. After the priority staffing, progress staffings are held weekly. The priority staffing is the cornerstone of the Case Management Supervision (CMS) plan. When a case reaches the mid-point in the program the defendant's performance is reviewed. At this time, any changes in treatment, sanctions or termination, as well as the goals to be met for completion of the program, are discussed.

Client Assessment. Client assessment is an ongoing process and is critical during the first days the defendant is in the program. Needs of the defendant are determined by input from the supervision team, applicable community-based programs, collateral sources and the defendants themselves. The defendant's needs are identified, prioritized, and addressed with a clearly defined supervision strategy. Assessment criteria considered include education/vocation, substance abuse, mental health, family issues, employment, physical health, legal or financial matters, religious needs and reintegration into the community.

Client Contact. Three different levels of client contact are provided, one level for each of the following three program phases:

Phase I-Orientation. This phase lasts approximately one to two weeks, depending on the defendant's needs. Program work and scheduled daily contact with DRC staff begin. A minimum of two field contacts per week are made. By the end of this phase, the Case Management Supervision plan is complete. Daily reporting 
means that the defendant is seen five out of seven days per week at the office or in the field. The Adult Probation staff is responsible for the contact. Contact in the field is "random" as to day of week and time of day so the offender cannot plan them. This requires early morning or late night visits, including double-backs when necessary by the supervision team.

Phase II-Program. The majority of the defendant's work and programming occurs during this phase. The average stay in this phase is six to eight weeks. A minimum of two field contacts are made per week with supplemental contacts occurring based on individual needs. The defendant is required to report to the DRC as directed by the supervision team.

Phase III - Transition. During the final two weeks of the defendant's stay in the DRC, an exit interview is conducted for the purpose of compiling a future supervision strategy. Ideally, this includes the defendant, the DRC team, and the newly assigned officer. A minimum of one field contact per week occurs during this level, with office reporting as needed. Staff provides a final assessment of each defendant prior to the transfer of the case. The last day in the program is typically determined by the jail release date though offenders may be "extended" in the program. In cases where "soft time" is given, and the release date is unclear, the calculation of time is reviewed with the supervisor and jail staff to coordinate an accurate release date.

Employment and Collections Procedure. It is expected that all DRC defendants be employed and/or enrolled as a student. DRC defendants must have a Letter of Understanding completed by their employer within five working days of obtaining employment. If the DRC defendant committed an offense that could potentially be a conflict with the employer, such as a theft charge, the employer must complete a letter indicating that they have a detailed understanding of the defendant's offense and the liability of employing the individual. This letter is also submitted with the Letter of Understanding within five working days of employment. All employed DRC defendants pay DRC program fees at the rate of one hour's gross wage per day plus a two dollar daily administrative fee with a minimum payment of $\$ 7.00$ per day. Defendants pay program and Court fees by surrendering their paycheck or submitting money orders. The supervising officer decides as to the manner of payment after consulting with the DRC supervisor. At the time of orientation, any employed DRC defendants who have not been in a furlough program have a Payment Disbursement Form completed and sent to Administrative Account Services along with a copy of the defendant's Terms and Conditions of Probation.

If a DRC defendant is unemployed, payments are made at the discretion of the supervising officer. However, if the supervising officer feels that the defendant is not making every effort to find employment, a payment schedule is maintained in order to motivate the individual to find work. All defendants are expected to make some payment regardless of their employment or financial circumstances. 
Work Furlough defendants who enter the DRC Program on Tuesdays pay in advance through the Saturday of that same week. Upon transfer into the DRC Program, defendants' monies are handled through the Intensive Probation Supervision account. Work Furlough defendants are expected to be current on their furlough fees before being accepted into the DRC. The defendant is responsible to pay all accrued delinquencies from the Work Furlough Program while participating in the DRC.

DRC fees are only modified or waived with the written approval of the DRC supervisor. The supervising DRC Officer documents the DRC defendant's inability to pay full fees while in the program. Modification of furlough fees is not allowed without the written approval of the DRC supervisor. For modification of fees to be considered, the defendant must provide documentation and complete a Payment Ability Form and submit it to the supervising officer. If approved by the supervisor, this information is submitted to Administrative Account Services along with a disbursement form.

Account services provides DRC staff with a weekly list of defendant's whose records show them to be delinquent in the payment of program fees. Officers receive this delinquency list on Wednesday afternoon, and have until the following Monday at noon to review it and make necessary corrections with account services. If a defendant is delinquent, the supervision team addresses this and takes appropriate steps to resolve the problem.

Disciplinary Action. For technical violations that do not require removal from the program or permanent return to custody, the supervision team utilizes intermediate sanctions when appropriate. This may include:

- Increased/more severe restrictions

- Increased surveillance

- Community Restitution hours

- Case management staffings with the DRC supervisor, supervision team, and the defendant

- Placement in Garfield Residential Center

- A temporary return to custody (7-14 days) followed by return to the program

Technical violations that require the defendant be returned to custody are staffed with the DRC supervisor. When a DRC defendant is removed from the program during the jail phase, the supervision team has the option of arresting or directing the defendant to self-surrender. The defendant is directed to self-surrender only in those cases when there has been some compliance, and it appears likely that they shall comply with a self-surrender without causing problems. If the defendant is directed to self-surrender, the Return to Custody and Jail Booking Forms are completed. The defendant is rebooked into jail under the original booking number. The defendant takes this paperwork along with the Order of Confinement and the written directive 
with instructions for self-surrendering by a specific time. Probation staff then advises jail staff of the approximate time the defendant is to arrive at jail. If the defendant does not fit the self-surrender criteria, the DRC supervision team follows standard arrest procedures. The arresting officer is given the original of both forms along with the defendant's Order of Confinement to give to the Maricopa County Sheriff's Office. An Arrest Incident is completed and sent to DRC Administration within two working days of the arrest. Furlough Accounting and, if applicable, the officer who received the case are notified.

Upon notice that the whereabouts of a defendant cannot be accounted for, and reasonable efforts to locate the defendant are unsuccessful, the defendant is considered to be an absconder. A Petition to Revoke Probation with a Warrant are walked through by the next working day. Furlough Accounting and, if applicable, the field officer who would have received the case are notified. If the defendant commits a new criminal offense, the case is staffed immediately with a DRC supervisor. The DRC supervision team is responsible for requesting all Warrants and filing Petitions to Revoke Probation for technical violations and for committing a new crime while the defendant is in the program.

Case Transfers. All efforts are made to have contact with the newly assigned probation officer during the final Phase and soon after completion of the program. If no field probation officer has been assigned, the Officer of the Day at Presentence is called for probation officer assignment. This is done at least two weeks before the defendant leaves the program. If there is a field probation officer already assigned, the case goes back to that officer, provided the defendant resides in the officer's assignment area; otherwise, the case is considered for random assignment. Copies of all incidents, contact sheets, and weekly schedules are sent to DRC Administration for data entry.

A transition summary is then completed. This includes a description and assessment of the directed supervision strategy, a description of ongoing programming and a recommendation for future supervision. All incidents, contact sheets, schedules, and other documents are placed in the file.

In the event the defendant does not report to the newly assigned officer as directed, and efforts to locate the defendant fail, the defendant is considered an absconder. The "most knowledgeable probation officer" standard is applied. In most cases, this means the DRC supervision team is responsible for completing a Petition to Revoke and dealing with future related Court matters.

Each offender's progress through the DRC program is documented. Standards for caseload documentation are provided in Appendix A.

\section{STANDARD PROBATION DESCRIPTION}

Generally, DWI offenders who receive standard probation (including those in this study's comparison group) receive written or telephone contact from their assigned 
probation officer near the end of their period of incarceration. At this time, an appointment is made for their first meeting with the probation officer and they are instructed to bring certificates of counseling and treatment they may have received while incarcerated to that meeting.

At the initial meeting, the probation officer reviews the terms of the probation, (which require them to abstain from alcohol and comply with counseling and treatment regimens), confirms their living and working circumstances, and refers them to a treatment provider.

Persons on standard probation then are required to meet with their probation officer on a monthly basis throughout their probation. Typically, probation officers also visit the probationers at their residence a minimum of once every three months. Probationers are charged probation fees of $\$ 30$ to $\$ 40$ per month.

Persons who participate in DRC go on standard probation after DRC and remain there until the end of their period of probation. 
EVALUATION OF A DAY REPORTING CENTER FOR DWI OFFENDERS 


\title{
3 - EVALUATION
}

\begin{abstract}
APPROACH
Our basic approach to the evaluation was similar to that used in two other evaluations of alternative sanctioning programs we have performed recently for NHTSA (Jones, Wiliszowski, and Lacey, 1997; Jones and Lacey, 1998). The evaluation had two components, program operation and program impact. The program operation component dealt with the extent to which the program specifications (as summarized above in our program description) were actually being achieved. This aspect of an evaluation is often referred to as an administrative evaluation. Our approach was to query DRC program staff on the particulars of their activities to obtain data on gross measures of program activity (for example, number of clients entering the program per unit time and their mean time in the program) from program staff.

The program impact component was the major concern of the evaluation. It sought to determine the effect of the DRC program on the future drinking-driving behavior of program participants. The measure we used for future drinking-driving behavior was the time from a client's entry in the program to another DWI arrest.

The design and results of each of these components are described below.
\end{abstract}

\section{PROGRAM OPERATION}

We studied the DRC program's effect on the 177 DWI offenders studied in this project (see discussion of the impact evaluation below). Table 3-1 shows the number of DWIs entering the program during the period studied. Only 12 persons entered DRC in the first two years, but activity increased in the third year (1994), rising to 64 in 1996 and dropping down to 25 in 1997.

On average, the offenders were sentenced to 38 months of probation (including time both during and after DRC), and served 24 months. The figure for months served is colored by the fact that few of those entering DRC in 1996, and none of those entering in 1997 had completed their probation by the end of 1997 (Table 3-2). Actually, some of the offenders never completed their probation because of violations of the terms of probation.

By comparison, the offenders in the standard probation comparison group had slightly longer terms of probation: 44 months sentenced and 26 months completed. The variation of percent completing probation by year was similar to that of the DRC group. 
Table 3-1: Number of Study DWIs Entering the DRC Program by Year

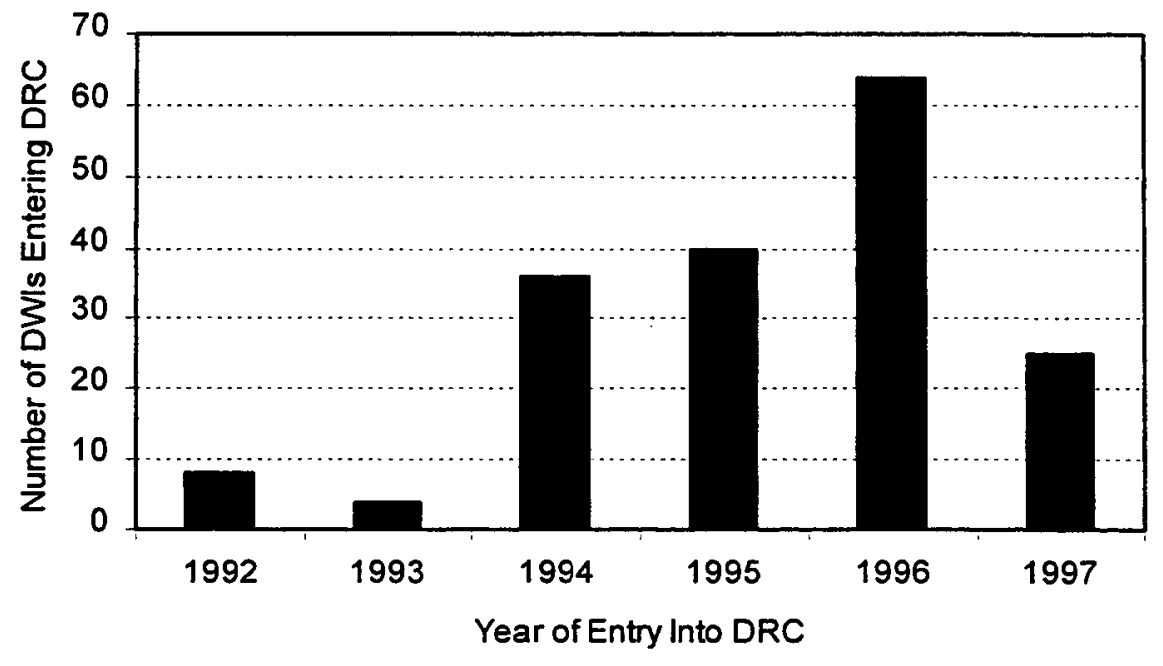

Table 3-2: Mean Months Sentenced to Probation and Mean Months Served by DRC Subjects Studied

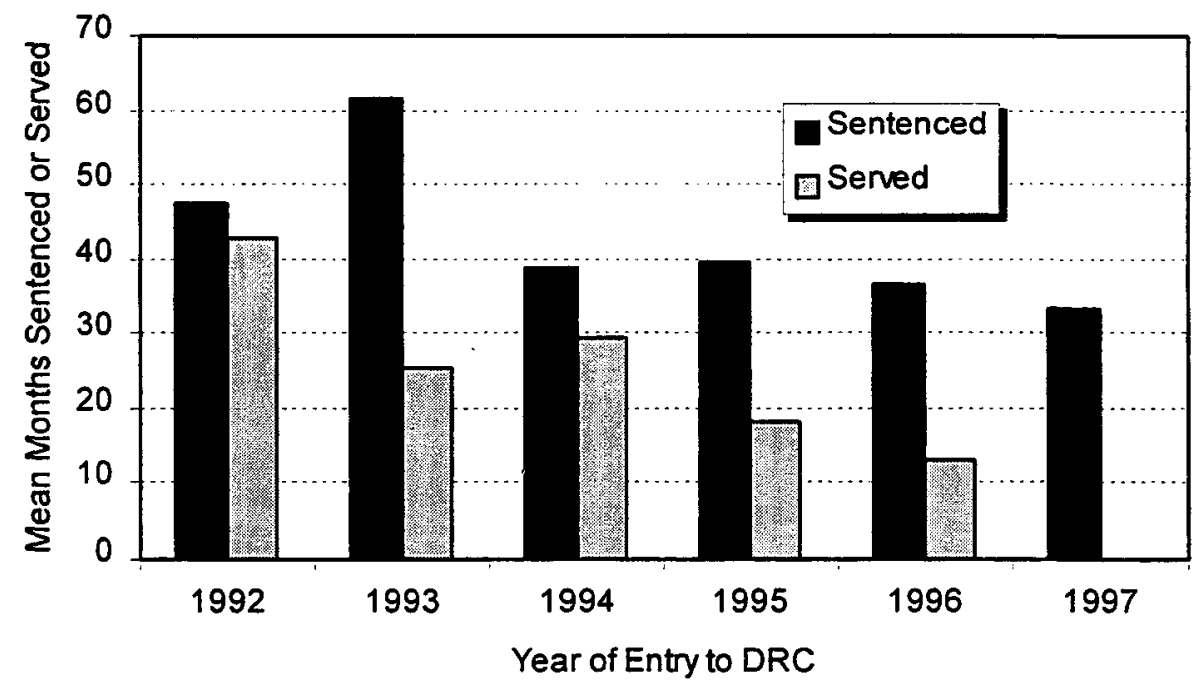


Program staff reported that the program ran in accordance with the procedures described in Chapter 2. The only major problem experienced (from the APD viewpoint) was due to the requirement that the County Attorney approve participants APD had selected for the program, sometimes resulting the exclusion of offenders APD believed would benefit from the program.

Finally, we examined cost of the DRC program as compared to standard probation. Data from APD indicate that it costs $\$ 36.79$ per day per individual to keep an offender in the Maricopa County jail versus $\$ 19.69$ per day for DRC. Since the DRC offender typically is incarcerated for sixty fewer days than comparison group members, a savings or $\$ 1,026(\$ 17.10 \times 60)$ per offender is realized from the DRC.

\section{PROGRAM IMPACT}

\section{Experiment Design}

The major research question addressed in this evaluation was:

What is the DWI recidivism of felony DWI offenders participating in the DRC program and how does it compare with the DWI recidivism of felony DWI offenders given a traditional sentence?

The statewide recidivism of the DRC group was compared to that of a group composed of felony DWI offenders who received standard probation (the comparison group). DWI recidivism is defined here as the probability of the occurrence of the first subsequent DWI conviction ${ }^{2}$ on or before time $\boldsymbol{T}$. For the DRC group, $T=0$ is the time when the offender entered the DRC program after release from jail, and for the standard probation group, $T=0$ is the time when the offender entered standard probation after release from prison.

Since subjects were not randomly assigned to the two groups, analytic adjustments of the data were made to account for possible differences between the test group and the comparison group. A number of covariates (listed below) were available for adjusting the modeled recidivism.

\section{Data Sources}

Data were provided by two sources. The Adult Probation Department of the Superior Court of Maricopa County provided files containing the probation records of both groups of offenders, and Arizona Motor Vehicle Department (MVD)

\footnotetext{
${ }^{2}$ Arrest dates were not contained in the database we obtained from the Arizona Motor Vehicle Department.
} 
provided the driver records of both groups. All of the subjects entered their program during the period 1992 through 1997.

Driver records data containing the dates of all recorded DWI convictions were merged with the probation records, enabling us to determine the date of the index offense, the number of DWI convictions prior to the index offense, and the time from the program entry date to the first subsequent DWI conviction, if any. The final analysis file contained 2,841 records, 176 for the DRC group and 2,765 for the comparison group. Variables contained in the analysis file were:

- Group (DRC or Comparison)

- Alcohol Abuser (yes or no)

- Program Entry Date

- Program End Date

- Actual time on Probation

- Date of Birth

- Time to First Subsequent DWI

- Education Classification

- Ethnicity

- Number of Past Felonies

- Number of Past Juvenile Offenses

- Marital Status

- Number of Past Misdemeanors

- Number of Prior DWIs

- Occupational Status

- Number of Past Prison Sentences

- Number of Past Probations

- Offender Sex

Other variables were constructed from these variables for use in the analysis.

\section{Analysis Techniques}

The primary technique used for the impact analysis was survival curve analysis. This technique allows the study of complex time patterns of recidivism, for example, a recidivism rate that is initially low, but higher later.

The formal factor reflecting the evaluation design was a variable indicating whether the subject belonged to the treatment group or the comparison group. Factors available for use in controlling for differences between the treatment and comparison groups (that is, the analytical "matching" of the two groups) are indicated in the above list.

In the survival analysis, we used the time from program entry to the first "failure" (DWI conviction) as the dependent variable. The time-varying recidivism (that is, probability of a failure) as a function of group (DRC or comparison) was of primary 
interest. The analysis was designed to indicate whether there was any difference in recidivism with respect to group and if so, the direction and amount of the difference, and also the probability $\boldsymbol{p}$ that the difference was due to chance alone. We also ascertained whether various subgroups (for example, young offenders and old offenders) had differing recidivism times with respect to group. The statistical techniques contained in the SAS ${ }^{\circledR}$ PHREG procedure were used in the analysis.

We also performed a collateral analysis to determine which offender attributes of the combined group (DRC plus standard probation) were associated with a higher probability of recidivating within two years after program entry. The CHAID procedure developed for the SPSS $^{\circ}$ statistical package was used in the multivariate analysis. Independent variables included were sex, age, race, educational level, employment status, marital status, number of prior DWIs, months on probation, number of prior probations, number of prior prison sentences, number of prior felony offenses, number of prior misdemeanor offenses, number of prior juvenile offenses, and whether or not an alcohol abuser. The dependent variable was the percentage of the combined group recidivating after two years.

Results

Recidivism. The raw recidivism curves (unadjusted for differences between the two groups) are shown in Figure 3-1 below.

The two curves are approximately the same up for about the first 18 months. From 18 months though about 45 months the curve for the DRC group is about 1 to

Figure 3-1: Raw Recidivism Curves for the DRC Group and the Comparison Group

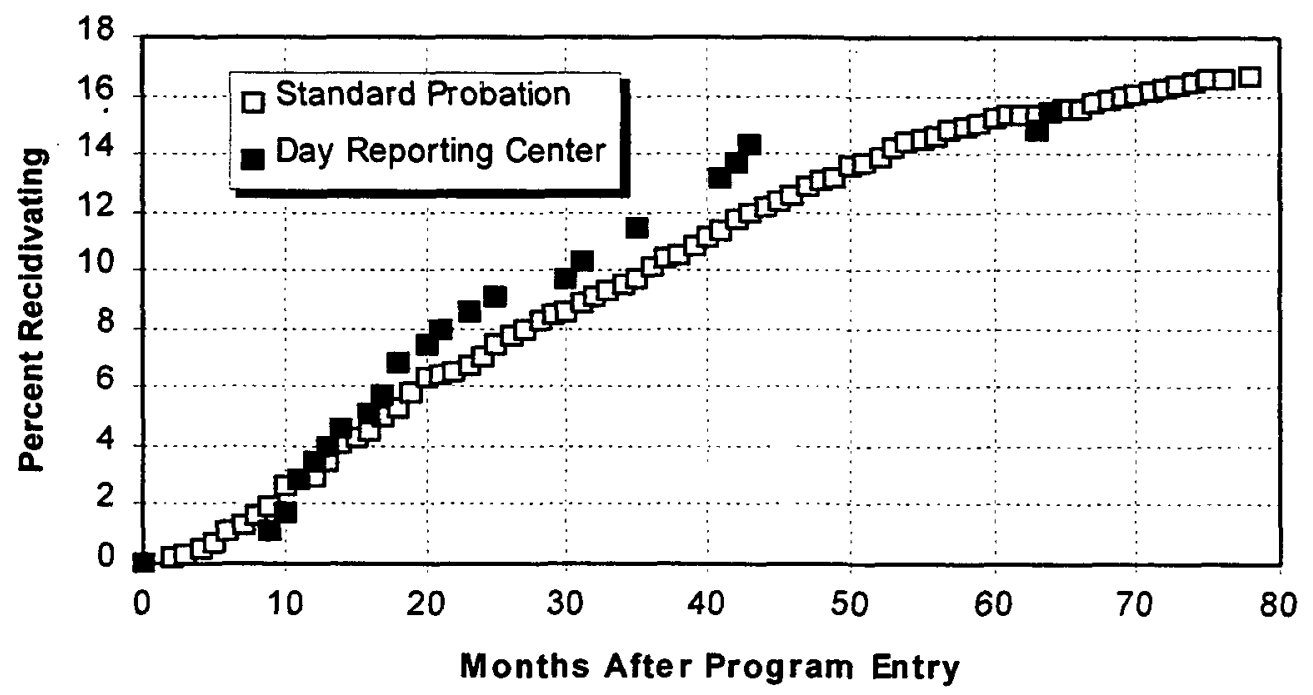


2 percentage points higher than the curve for the comparison group. At 65 months, the two curves coincide.

The formal recidivism analysis adjusted the raw recidivism rates for group differences in such covariates as client age, sex, and prior DWIs, among others. It also allowed us to determine whether any difference in the recidivism rates of the two groups was statistically significant, that is, not due to chance alone. The model showed that the following covariates had a statistically significant effect on recidivism, and were retained in the recidivism model:

\begin{tabular}{lc}
\multicolumn{1}{c}{ Covariate } & $\boldsymbol{p}$ \\
\hline Number of Prior DWIs & 0.0166 \\
Sex & 0.0193 \\
Age & 0.0001 \\
Time on Probation & 0.0237 \\
Time Sentenced to Probation & 0.0518 \\
Number of Prior Felonies & 0.0054
\end{tabular}

In the table, $\boldsymbol{p}$ is probability that a covariate's effect on recidivism was due to chance alone. A value of 0.05 or lower is usually taken as being "statistically significant." Note that offender race did not have a significant effect on recidivism.

Of primary interest, though, is the variable "group," where the DRC group was assigned the value of 1 , and the comparison group was assigned the value of 0 in the PHREG model. The $p$ value for "group" was 0.2565 , nowhere near the level required for statistical significance. Thus, the survival analysis indicated that there was no significant difference between the recidivism of $D R C$ group and that of the standard probation comparison group.

The number of prior DWI offenses affected the recidivism of both groups. Figure 3-2 shows the percent of the combined groups that had recidivated after two years plotted versus number of prior DWIs.

Figure 3-2: Percent of Combined Group Recidivating After Two Years By Number of Prior DWIs

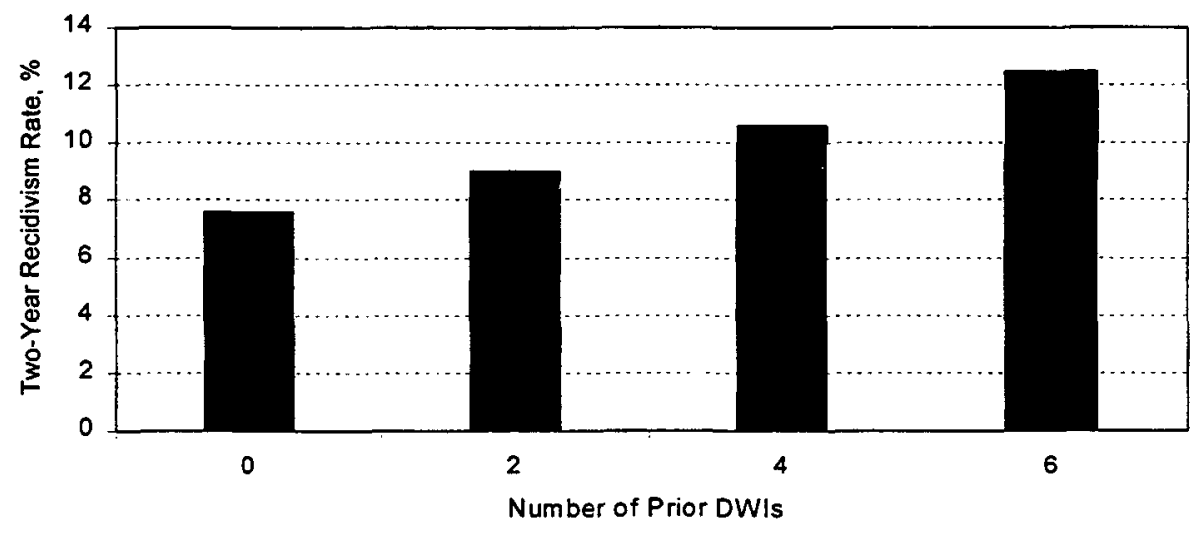


From the figure it can be seen that $8 \%$ of offenders with two priors had been convicted of another DWI after two years. However, nearly $13 \%$ of offenders with with six priors (by any measure, "hard-core" offenders) had been convicted of another DWI after two years.

Offender Characteristics. The CHAID analysis examined the characteristics of the combined group of offenders. Specifically, it attempted to identify the characteristics of offenders with very high and the characteristics of offenders with very low recidivism rates after two years. Variables found to be significant at the 0.05 level in identifying such characteristics were:

- Age,

- Sex,

- Time on probation,

- Employment status,

- Number of prior probations,

- Race,

- Alcohol abuser, and

- Prior DWIs.

Four groups having much higher recidivism rates than the overall two-year recidivism rate of $8 \%$ were identified. They were:

\section{Group 1 - $14.9 \%$ recidivating}

age $35+$ years; 1 to 3 prior probations; non-white collar; non-white race; 2 prior DWIs

\section{Group $2-14.4 \%$ recidivating}

age $<35$ years; male sex; $1+$ prior probations

\section{Group 3 - 13.4\% recidivating}

Age $35+; 4+$ prior probations

\section{Group $4 \mathbf{- 1 1 . 8 \%}$ recidivating}

age $<35$ years; male sex; no prior probations; not an alcohol abuser

Two groups had very low recidivism rates after two years. They were:

\section{Group $5-1.7 \%$ recidivating}

age $35+$; no prior probations, white collar

\section{Group $6-2.1 \%$ recidivating}

age $<35$; female sex 
These results should be of interest to probation departments in selecting treatment and rehabilitation regimens for clients as well as to researchers in selecting target groups for future studies of repeat DWI offenders.

\section{SUMMARY AND CONCLUSIONS}

We examined the DWI recidivism of DRC participants compared to the recidivism of other similar offenders assigned to standard probation. We found no significant difference in the recidivism of the two groups, the analyses indicating that, if anything, the recidivism of the DRC group might be slightly higher than that of the standard probation group.

This is not necessarily a negative finding in regards to the DRC program. The DRC group consisted of persons who were released from jail early to participate in the program. They generally were in the DRC program for a period equivalent to their remaining jail time. They were evaluated and received treatment and other services such as job skills training, educational services and the like while in the DRC program. The comparison group consisted of offenders who served their full term of incarceration either in jail or prison. Those in jail were referred to counseling or treatment after release from incarceration. Those in prison generally received treatment early in their period of incarceration and were referred to further treatment after release.

Thus all persons received treatment, though at different points in the sanctioning process. However, offenders who have been incarcerated in the Department of Corrections (DOC) complete mandatory alcohol assessment and treatment in prison while the DRC and Youthful Offender Program offers substance abuse treatment that is not alcohol specific. Thus, the DRC group in our study may be at a treatment disadvantage in that they are placed in drug offender groups for treatment as opposed to a treatment program tailored to deal with alcohol specifically. Additionally, DRC cases are screened to be lower risk DWI offenders to be eligible for the program. The DOC group may have a lower level of denial after alcohol specific treatment and incarceration while the DRC group may perceive themselves as not having a serious problem. If alcoholism denial is a key factor in recidivism, then the DRC group may be at a disadvantage in this study.

However, one of the key programmatic virtues of the DRC program besides its intent to ease the transition of offenders back into society is that it is a lower cost program than either form of incarceration and thus is less costly to the overall sanctioning system. 


\section{4 - CONCLUSIONS AND RECOMMENDATIONS}

The main focus of this study was to examine the effectiveness of the Day Reporting Center program followed by probation as a countermeasure for severe DWI offenders as an alternative to longer incarceration in prison or jail followed by probation.

We conclude that the DRC group had essentially the same statewide conviction rate for alcohol related traffic violations as the comparison group. However, other measures of effectiveness yielded more positive results.

Several aspects of the DRC program are not intended to address DWI recidivism directly, but rather are intended to assist in the reintegration of these offenders into society. These include insistence on employment, demonstration of responsibility through at least partial payment of fees, and participation in educational programs as appropriate. Further, the cost providing of correctional services through DRC is significantly less that jail. In Maricopa County it costs $\$ 36.79$ per day per individual to keep an offender in jail versus $\$ 19.69$ per day for DRC. The DRC offender typically is incarcerated for sixty fewer days than comparison group members who completed their period of incarceration followed by standard probation. This $\$ 17.10$ per day savings translates into $\$ 1,026$ per offender if they are in DRC rather than jail.

Thus, the DRC program saves on average about $\$ 1,000$ per offender. Participants become employed and thus provide support for themselves and their families. Undereducated adults benefit from additional educational services. Treatment needs are addressed. Consequences for uncooperative or non-compliant behaviors are immediately imposed.

This study also sought to determine whether DWI offenders were appropriate for a DRC-type program, which is intended for offenders thought to be of low risk of committing violent crimes. Interviews with program staff indicated that DWI offenders did participate in the DRC program and were appropriate participants. One area where the program might be modified to more effectively deal with DWI offenders is in the treatment aspect of the program. The vast majority of these severe DWI offenders are alcohol abusers rather than abusers of other drugs. The program we studied, included a general substance abuse treatment component. If the DWI caseload in DRC were expanded, then it would be appropriate to screen for problem drinking and implement treatment modalities specifically tailored to alcohol abuse and drinking driving.

We understand that there is some reluctance to use DRC for DWI offenders because, though by traditional measures they meet the criteria of low risk offenders, they are believed to pose a risk to society through potential drinking and driving while participating in the program. However, this study indicates that they pose no greater risk than those who serve their full jail or prison terms, and that it costs society less to deal with them in DRC than in jail or prison. 
We recommend that consideration be given to referring more DWI offenders to DRC-type programs and that the DRC treatment program be modified to include a treatment regimen which is structured to deal specifically with alcohol abuse and driving. 


\section{5 - REFERENCES}

Arstein-Kerslake, GW; and Peck, RC. (1985). Topological analysis of California DUI (driving under the influence) offenders and DUI recidivism correlates. Sacramento: California State Department of Motor Vehicles.

Donovan, DM; Umlauf, RL; and Salzberg, PM. (1990). Bad drivers: identification of a target group for alcohol-related prevention and early intervention. Journal of Studies on Alcohol 51(2):136-141.

Fell, JC. (1991). Repeat DWI offenders: their involvement in fatal crashes. In: Intoxicated Drivers: Multiple and Problem Offenders' Conference. Stevens Point, WI, 5-6 September, 1991. Washington, D.C.: National Highway Traffic Safety Administration.

Jones, RK; Joksch, HC; and Wiliszowski, CH (1991). Implied consent refusal impact. Washington, D.C.: Report No. DOT HS 807 765. National Highway Traffic Safety Administration.

Jones, RK.; Wiliszowski, $\mathrm{CH}$; and Lacey, $\mathrm{JH}$ (1997). Evaluation of alternative programs for repeat DWI offenders. Report No. DOT HS 808483 . Washington, DC: National Highway Traffic Safety Administration.

Jones, RK; and Lacey, JH. (1998). Evaluation of an individualized sanctioning program for DWI offenders. Report No. DOT HS 808 842. Washington, D.C.: National Highway Traffic Safety Administration.

Jones, RK; Joksch, HC; Lacey, JH; and Schmidt, HJ (1988). Field evaluation of jail sanctions for DWI. DOT HS 807 325. Washington, D.C.: National Highway Traffic Safety Administration.

Morris, N; and Tonry, M (1990). Between prison and probation. Intermediate punishments in a rational sentencing system. New York: Oxford University Press, Inc.

U.S. Department of Justice. (1990). A survey of intermediate sanctions. Washington, D.C.: U.S. Department of Justice, Office of Justice Programs.

Wiliszowski, CH; Murphy, PV; Jones, RK; and Lacey, JH (1996). Determine reasons for repeat drinking and driving. Report No. DOT HS 808401. Washington, D.C.: National Highway Traffic Safety Administration. 
EVALUATION OF A DAY REPORTING CENTER FOR DWI OFFENDERS 


\section{APPENDIX A - Standards for DRC Caseload Documentation}

DRC is a program involving the supervision of defendants who are considered part of the jail population, necessitating that all documentation be done in a timely and comprehensive manner. Incidents requiring documentation include:

-All probation violation actions.

-New arrests.

-Modifications.

-Court orders and minute entries.

-Changes in supervision strategy when plan proves to be ineffective or no longer viable.

-Justification for changes in phase.

-Entry, into, departure from, or refusal to cooperate in treatment programs.

-Completion of special terms of probation.

-Changes in employment and address.

-Jail bookings and release dates, marriages, suicide attempts, psychotic episodes, and all other non-routine or out-of-the ordinary events (e.g., hostile attitude or threats by defendants, family problems, and divorces).

-Any missed scheduled event.

-Receipt of Letter of Understanding signed by the employer.

-Roll-ups. A special Arrest Incident Form is to be completed.

Most field contacts are routine, but occasionally they do require more information than simply stating a contact was made. For the purposes of this program certain documentation is made in order to avoid manipulation by the client. Field book entries must include:

-Directives.

-Changes in schedule.

-Requests for changes in schedule.

-Any reference to an incident.

-Any rule violation.

DRC defendants are not only under house arrest, they are in custody. Before an officer issues a travel permit or submits a Petition to Modify Probation, the case is staffed with the supervisor. Out-of-state travel requires a Petition to Modify Probation, releasing the defendant from custody and allowing the defendant to travel out of state. The Petition reflects the dates of travel and when the defendant is to be returned to custody. The time the defendant is absent is not counted toward the time incarcerated. Out-of-state travel is verified and documented. Out-of-county travel is verified and documented. An exception is temporary work that does not require the 
defendant to be out of the county overnight. A Petition to Modify Probation is not required if the defendant is only absent for the day. If the defendant is absent for more than 24 hours, a Petition to Modify Probation is required. 


\section{DRC COMPLIANCE AGREEMENT}

1. I understand that the Day Reporting Center (DRC) is a jail furlough Program. I will conduct myself in accordance with the laws, terms of probation, and the rules of the DRC program. Failure to comply could result in my return to the Maricopa County Jail.

2. In the event of an emergency, any unforeseen difficulty or change of schedule, I will contact a DRC staff member immediately.

3. At all times I will carry a state-approved identification card.

4. I understand that I am required to complete a daily schedule, approved by the DRC staff. If I leave from or fail to report to any location such as place! of employment, education, counseling, or home without authorization of the DRC staff, I may be considered as missing from the program or as, an escapee. This may result in my termination from the program and possible new criminal charges.

5. I will travel directly to my approved destination with no stops or detours along the way.

6. I understand that my place of residence must be approved and is subject to frequent verification. Failure to be at said residence during designated times may be considered a major violation. I agree to be accessible to any staff member(s) of the DRC who attempt to contact me whether in person or by telephone. I also grant authorization of any probation or surveillance officer to search myself or my property.

7. I will not use illegal drugs, illegal substances or alcohol while in the program. I will get permission from my supervision team prior to taking any prescribed or over-the-counter medication. I also understand that I will be subject to drug and alcohol testing.

8. I will not possess, control, or own any firearm, ammunition, explosive, deadly weapon, or prohibited weapon.

9. I understand that I am responsible for providing my own transportation, public or private, and that the DRC staff must approve all transportation arrangements including vehicle, driver and route. I will not operate a motor vehicle without first providing DRC staff with a copy of my valid Arizona Driver's License, proof of insurance, current registration and complete vehicle description. I will drive no other vehicle without prior approval of the DRC staff.

10. Other than for authorized DRC functions, I understand that while on furlough I will not associate with or contact in any manner any person known to have a criminal record without prior approval of the supervision team.

11. If I am sick or otherwise unable to work or report to the DRC, I will notify and obtain approval from DRC staff. If working, I will notify my employer of my inability to work in accordance with the rules of my place of employment. I will remain at home for the remainder of the day.

12. I will advise any prospective or current employer of my offense and 
involvement with the DRC prior to accepting a job. I also authorize DRC staff to contact and exchange pertinent information as necessary to monitor my program performance and discuss my current status with prospective employers and other program sponsors.

13. I authorize my employer to disclose and release to DRC staff any information regarding my employment.

14. I will not enter into any civil contract or incur any indebtedness without the approval of my DRC supervision team.

15. I understand that I am required to inform DRC staff of any charges pending against me, including traffic matters. I agree to appear as scheduled for all Court hearings.

16. I understand that any acts or threats of violence by me to any person may result in my removal from the program.

17. I will attend any program of assistance, including participation in the Community Restitution Program, as directed by the DRC staff.

18. I understand that there is a charge of one hour's gross wage per day, plus a $\$ 2.00$ daily administrative fee to defendant in the DRC. The amount I will be responsible for paying will be determined by my ability to pay and a financial evaluation completed by DRC staff.

19. I understand if I am under 26 years of age, I will be placed in the Youthful Offender Program and will be required to attend service prograns which may go beyond my originally scheduled jail release date.

I have read and/or have had explained to me fully, and understand the above rules and regulations and agree to fully abide by them. I understand that any deviation may result in my removal from the program. I have received a copy of this agreement.

Client Signature

Date

D.R.C. Staff Signature

Date 


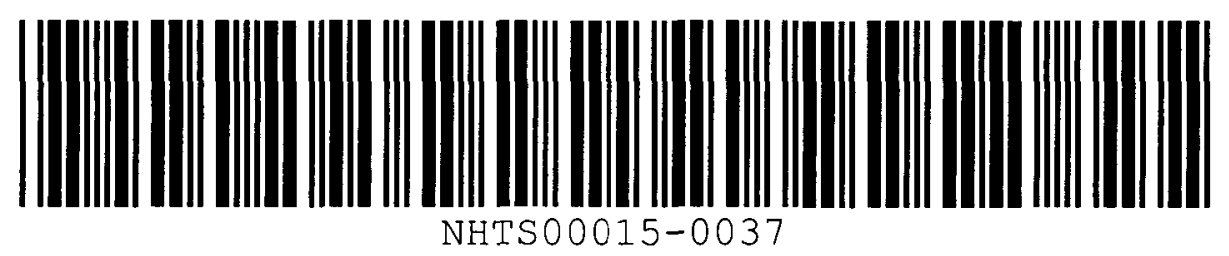

NHTSA

BOX 00015

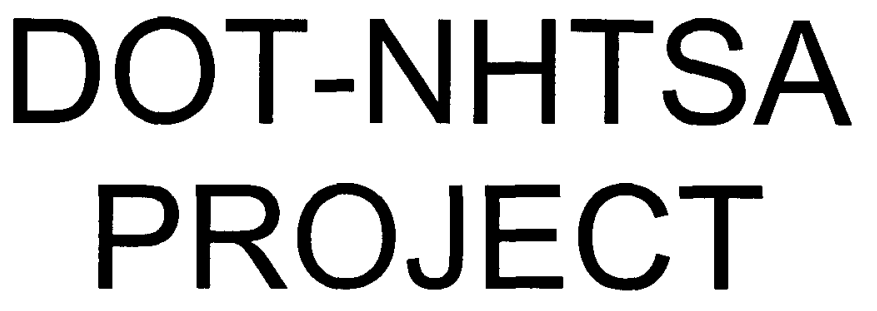


DOT HS 808989

August 1999

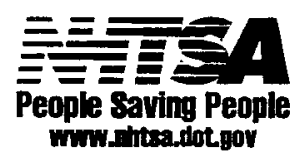

